\title{
Evaluation of Efficiency of Primary Medical and Health Institutions Based on DEA and Entropy Weight TOPSIS
}

\author{
Nannan Tan, Yong $\mathrm{Li}^{*}$ \\ School of International Pharmaceutical Business, China Pharmaceutical University, Nanjing, China \\ Email: ${ }^{\star L s g y 168 @ 163 . c o m ~}$
}

How to cite this paper: Tan, N. N., \& Li, Y. (2020). Evaluation of Efficiency of Primary Medical and Health Institutions Based on DEA and Entropy Weight TOPSIS. Open Journal of Social Sciences, 8, 89-98. https://doi.org/10.4236/jss.2020.87008

Received: June 12, 2020

Accepted: July 10, 2020

Published: July 13, 2020

Copyright $\odot 2020$ by author(s) and Scientific Research Publishing Inc. This work is licensed under the Creative Commons Attribution International License (CC BY 4.0).

http://creativecommons.org/licenses/by/4.0/

\begin{abstract}
China's primary health care system is the key to guaranteeing and implementing the "full coverage, basic protection" social medical policy. This study uses the DEA model and the entropy-weight TOPSIS method to estimate the efficiency of China's primary medical and health institutions in 2018. The results found that in 2018, the overall mean score of the efficiency of primary medical and health institutions was low, and the inter-provincial differences were large. As for the policy implication behind this paper, responsible government departments in China should fully distribute health resources rationally and improve the primary medical and health service system.
\end{abstract}

\section{Keywords}

Primary Medical and Health Institutions, Efficiency, DEA, Entropy Weight TOPSIS

\section{Introduction}

Primary medical and health institutions in China include community health service centers (stations), street health centers, township health centers, village clinics, outpatient departments, clinics (infirmary), accounting for more than $93 \%$ of the total number of medical and health institutions in China. Primary medical and health institutions play an important role in improving the flow of patients to hospitals, reducing health expenditure, and improving the efficiency of health system services (Fang, Jiang, Yang, \& Su, 2016; Wang, Yao, \& Tian, 2017). In October 2014, the Third Plenary Session of the Eighteenth Central Committee ${ }^{\star}$ Corresponding author. 
emphasized the need to deepen the comprehensive reform of primary medical and health institutions and improve the networked urban and rural primary health care service operation mechanism (Chen, 2015).

At present, the number and quality of primary medical and health institutions in China have been improved to some extent, but the problems still exist in the following aspects: first, the low service capacity of primary medical care, reflected in the low proportion of professional doctors and medical equipment. As a result, the service output of primary medical and health institutions is low and has less attractiveness to patients. Second, the relative capacity of medical services in primary medical and health institutions continued to decrease. In other words, with time, hospitals are also developing rapidly and far faster than primary medical and health institutions, resulting in a widening gap between primary medical and health institutions and hospitals. This widening capacity gap may be the root cause of the source's loss in primary medical and health institutions (Niu, Zhang, Ye, \& Zhang, 2018). The possible causes of the above problems may be the limited effect of the implementation of graded diagnosis and treatment. The relative lack of human, material and other resources in primary medical institutions has led patients to choose large hospitals for medical treatment because of a lack of trust in the service capabilities of primary medical and health institutions. From the perspective of the government, it is mainly manifested in the imperfection of relevant policies. Insufficient investment and the medical insurance policy have not opened a clear gap between primary medical institutions and large hospitals. It has exacerbated the vicious circle of low utilization rate and waste of resources in grass-roots institutions.

Domestic scholars have done a lot of research on the efficiency of primary medical and health institutions in China, but the deficiencies are mainly: 1) Limited to the evaluation of efficiency in a certain region or institution, and less overall evaluation of the nationwide primary medical and health institutions; 2) Focusing on the unilateral evaluation of resource input or service output, and less research on the efficiency of primary medical and health institutions combining the two; 3) Limited to one method (DEA, SFA, etc.), few studies are using DEA-entropy weight TOPSIS to evaluate efficiency. Starting from the provincial level, this study conducts a horizontal analysis and comparison of the efficiency of primary medical and health institutions in 2018. We found that the efficiency of primary medical and health institutions varies greatly between regions and the technical efficiency was low.

\section{Statistics and Indicators}

The data comes from the "2019 China Health Statistics Yearbook", from which the input and output data of health resources of 31 provincial units are obtained. Three input indicators and two output indicators are determined. The input indicators are the number of primary medical and health institutions, the number of health personnel, and the number of beds; the output indicators are the number of diagnosis and treatment and the number of admissions. 


\section{Methods}

The input-oriented BBC model and entropy weight TOPSIS were used to analyze the efficiency of primary medical and health institutions.

\subsection{Data Envelopement Analysis}

Data Envelopment Analysis (DEA) was founded in 1978 by Charnes, Cooper, and Rhodes to measure the relative efficiency of organizations with multiple inputs and multiple outputs. Traditional DEA models include the CCR model created by Charnes, Cooper, and Rhodes and the BBC model created by Banker, Charnes, and Cooper. The former model assumes that returns to scale are constant, that is, the calculated relative efficiency includes the scale efficiency part; the latter assumes that returns to scale are variable, that is, pure technical efficiency excluding scale efficiency. DEA can be divided into input-oriented and output-oriented according to different research needs. According to Cheng \& Qian (2012), when analyzing health efficiency, in the context of insufficient demand (that is when demand is the primary factor determining the number of health service outputs), choosing an output-oriented model makes it difficult to achieve the output goals identified in the projection analysis. At the same time, based on the theory of health production, the production technology of the health system is variable in returns to scale. Therefore, this paper uses the input-oriented VRS model to analyze the efficiency of medical and health resources.

\subsection{Entropy Weight TOPSIS}

A significant feature of the DEA model is that each decision-making unit (DMU) will choose the weight that is most conducive to its efficiency score, that is, under this group of weights, its efficiency score is the largest. Since the weight values selected by each DMU are different, these weight values cannot be directly used to compare or rank all DMUs, that is, the traditional DEA model cannot rank the effective DMUs (Xiong, Feng, \& Yong, 2016). Entropy weights comprehensively consider the basic information provided by each indicator, thereby calculating the indicator weight (Chen, Chen, \& Ma, 2012). The advantage is that each indicator value is objectively measured. The advantage of the TOPSIS method is that there is less loss of information in the calculation process, and it can more objectively reflect the differences inefficiency in health systems. Table 1 shows our weights, positive ideal solutions, and negative ideal solutions of indicators.

\section{Results}

\subsection{Description of Input and Output Indicators}

It can be seen from Table 2 that the scale of health resources in primary medical and health institutions in China is continuously enriched, which is specifically 
Table 1. Determination of the weight of input and output indicators.

\begin{tabular}{cccc}
\hline Indicators & Weight & $\begin{array}{c}\text { Positive ideal } \\
\text { solution }\end{array}$ & $\begin{array}{c}\text { Negative ideal } \\
\text { solution }\end{array}$ \\
\hline $\begin{array}{c}\text { Number of primary medical and } \\
\text { health institutions }\end{array}$ & 0.1572 & 0.0702 & 0 \\
Number of beds & 0.1705 & 0.0636 & 0 \\
Number of personnel & 0.1332 & 0.0528 & 0 \\
Number of diagnosis and treatment & 0.0995 & 0.0329 & 0 \\
Number of admissions & 0.1336 & 0.0935 & 0 \\
\hline
\end{tabular}

Table 2. Descriptive statistics of input and output indicators from 2013 to 2018.

\begin{tabular}{|c|c|c|c|c|c|c|}
\hline Year & Statistics & $\mathrm{X} 1$ & $\mathrm{X} 2$ & $\mathrm{X} 3$ & Y1 & Y2 \\
\hline \multirow{4}{*}{2013} & Max & 75,178 & 125,964 & 348,424 & $43,860.9$ & 496.6 \\
\hline & Minimum & 3898 & 3087 & 12,578 & 721.9 & 2.7 \\
\hline & Mean & 29,528 & $43,545.42$ & $113,361.1$ & $13,949.39$ & 138.7355 \\
\hline & median & 26,151 & 34,769 & 98,069 & 9854 & 92.8 \\
\hline \multirow{4}{*}{2014} & Max & 76,110 & 128,645 & 337,331 & 43,098 & 470 \\
\hline & Minimum & 3918 & 3052 & 13035 & 808 & 2 \\
\hline & Mean & $29,591.45$ & $44,554.74$ & $114,088.8$ & $14,077.26$ & 132.0968 \\
\hline & median & 25,994 & 35,295 & 93,386 & 10,082 & 98 \\
\hline \multirow{4}{*}{2015} & $\operatorname{Max}$ & 76,214 & 130,741 & 331,438 & 40,759 & 454 \\
\hline & Minimum & 3981 & 3198 & 13,366 & 798 & 2 \\
\hline & Mean & $29,702.26$ & $45,607.81$ & 116,231 & $14,006.26$ & 130.129 \\
\hline & median & 25,876 & 35,636 & 98,254 & 9754 & 93 \\
\hline \multirow{4}{*}{2016} & Max & 76,619 & 132,023 & 321,582 & 39,678 & 471 \\
\hline & Minimum & 3968 & 3218 & 14,097 & 777 & 3 \\
\hline & Mean & $29,887.68$ & $46,514.19$ & $118,792.3$ & $14,085.9$ & 134.3226 \\
\hline & median & 26,172 & 36,720 & 103,629 & 10,078 & 88 \\
\hline \multirow{4}{*}{2017} & Max & 78,207 & 139,395 & 325,310 & 41,582 & 519 \\
\hline & Minimum & 3966 & 3659 & 14,564 & 939 & 3 \\
\hline & Mean & $30,097.55$ & $49,307.35$ & $123,426.9$ & $14,286.74$ & 143.6452 \\
\hline & median & 26,378 & 38,538 & 106,310 & 10,045 & 96 \\
\hline \multirow{4}{*}{2018} & Max & 82,236 & 143,846 & 337,104 & 42,082 & 489 \\
\hline & Minimum & 4121 & 3771 & 16722 & 946 & 3 \\
\hline & Mean & 30,686 & $51,083.45$ & 127,895 & $14,214.03$ & 141.1613 \\
\hline & median & 26,423 & 39,933 & 110,358 & 10,033 & 90 \\
\hline
\end{tabular}

Note: X1: Number of primary medical and health institutions; X2: Number of beds; X3: Number of personnel; Y1: Number of diagnosis and treatment; Y2: Number of admissions. 
reflected in the growth of the number of health personnel and the number of institutions in 6 years, and the average number of beds in 2018 reached 51,083.45, compared with $43,545.42$ in 2013 , an increase of $17.3 \%$, indicating that China has increased its investment in health resources in primary medical and health institutions. In terms of the number of admissions, compared with 2013, there was a slight decline in 2014 and 2015, and then rebounded in 2016, 2017 and 2018. Overall, the total number of admissions is still increasing. In terms of diagnosis and treatment, there has been an increase in the past 6 years, which reflects the huge demand for primary health care in China. In general, the input and output of health resources in primary medical and health institutions have increased, but the wide gap between the maximum and minimum values of indicators also reflects the continuous widening of the differences among provinces.

\subsection{The Efficiency of Primary Medical and Health Institutions in 2018 under the DEA Model}

Table 3 shows our efficiency results under the DEA model. In 2018, the overall efficiency of DMUs was at a low level, with an average efficiency of 0.78 , and a large inter-provincial difference. Among the 31 regions in China, with the comprehensive efficiency value of 18 regions were relatively effective, namely: Beijing, Shanghai, Jiangsu, Zhejiang, Jiangxi, Hunan, Guangdong, and Chongqing. It shows that the input of primary health resources in these areas has reached the maximum output and was at the forefront of production. Among the 23 noneffective regions, the efficiency scores of Heilongjiang, Inner Mongolia, Jilin, Shanxi, and Tibet were lower than 0.5 , indicating that the input and output of primary health resources were in a relatively unreasonable state. And there were 14 regions, primary medical and health institutions efficiency at the "technologically ineffective" and "scale ineffective", which means that in the process of basic health resource allocation the problems of low efficiency and inadequate input scale exist at the same time. In other words, the allocation of health resources was affected by many factors, and there is still room for improvement in the future.

Under the condition of variable returns to scale, if the output is obtained based on the existing input, and the relative optimal output is achieved, it is called pure technical efficiency (Fang \& Zhao, 2013). Among the 31 regions in China in 2018, in addition to the above 8 relatively effective regions, there were Hubei, Sichuan, Henan, Tianjin, Shandong, Ningxia, Qinghai, and Tibet with a pure technical efficiency score of 1 . There was a total of 16 DMUs with pure technical efficiency, that is, to "relatively weak efficiency", accounting for $51.61 \%$ of the total DMUs. It can be considered that the utilization of primary health resources input in the above-mentioned areas is effective, and relatively optimal output has been obtained. The reason for the failure to achieve relative effectiveness is that the scale is not effective, prompting the need to adjust the scale of input. Overall, 
Table 3. Comprehensive efficiency, pure technical efficiency, and scale efficiency in 2018.

\begin{tabular}{|c|c|c|c|c|}
\hline Regions & $\begin{array}{l}\text { Comprehensive } \\
\text { efficiency }\end{array}$ & $\begin{array}{c}\text { Pure technical } \\
\text { efficiency }\end{array}$ & Scale efficiency & Scale returns \\
\hline Beijing & 1 & 1 & 1 & - \\
\hline Shanghai & 1 & 1 & 1 & - \\
\hline Jiangsu & 1 & 1 & 1 & - \\
\hline Zhejiang & 1 & 1 & 1 & - \\
\hline Jiangxi & 1 & 1 & 1 & - \\
\hline Hunan & 1 & 1 & 1 & - \\
\hline Guangdong & 1 & 1 & 1 & - \\
\hline Chongqing & 1 & 1 & 1 & - \\
\hline Hubei & 0.99 & 1 & 0.99 & drs \\
\hline Guangxi & 0.97 & 0.99 & 0.98 & drs \\
\hline Sichuan & 0.96 & 1 & 0.964 & drs \\
\hline Anhui & 0.96 & 0.96 & 0.99 & drs \\
\hline Henan & 0.90 & 1 & 0.9 & drs \\
\hline Yunnan & 0.88 & 0.88 & 1 & - \\
\hline Tianjin & 0.82 & 1 & 0.82 & irs \\
\hline Guizhou & 0.80 & 0.81 & 0.99 & irs \\
\hline Shandong & 0.80 & 1 & 0.80 & drs \\
\hline Hebei & 0.79 & 0.80 & 0.99 & drs \\
\hline Gansu & 0.77 & 0.82 & 0.94 & irs \\
\hline Fujian & 0.75 & 0.76 & 0.98 & irs \\
\hline Xinjiang & 0.69 & 0.74 & 0.93 & irs \\
\hline Shaanxi & 0.69 & 0.70 & 0.99 & irs \\
\hline Ningxia & 0.63 & 1 & 0.63 & irs \\
\hline Hainan & 0.63 & 0.89 & 0.71 & irs \\
\hline Liaoning & 0.59 & 0.63 & 0.94 & irs \\
\hline Qinghai & 0.51 & 1 & 0.51 & irs \\
\hline Heilongjiang & 0.47 & 0.52 & 0.92 & irs \\
\hline Inner Mongolia & 0.46 & 0.53 & 0.87 & irs \\
\hline Jilin & 0.43 & 0.50 & 0.86 & irs \\
\hline Shanxi & 0.42 & 0.45 & 0.93 & irs \\
\hline Tibet & 0.32 & 1 & 0.32 & irs \\
\hline Average value & 0.78 & 0.87 & 0.90 & - \\
\hline
\end{tabular}

Note: IRS represents increasing returns to scale, DRS represents decreasing returns to scale. 
the average technical efficiency was 0.87 , which was lower than the average score of scale efficiency. This shows that the medical results brought by health personnel and equipment in the primary medical and health institutions were low. It is suggested that the introduction of high-tech equipment and high-quality talents into primary medical and health institutions is an important method to improve the ability of primary health services.

In terms of scale efficiency, except for the 7 relatively effective regions, the scale efficiency score of Yunnan was also 1. For scale inefficiency, it can be divided into increasing returns to scale and decreasing returns to scale. Decreasing returns to scale means that the production efficiency is affected and resources are wasted due to the large scale. Seven regions showed a decreasing trend nationwide, including Hubei, Guangxi, Sichuan, Anhui, Henan, Shandong and Hebei, indicating that the existing primary health resources input in these provinces was higher than the general level and the input was higher than the output, suggesting the need to appropriately control the investment. At the same time, there were 15 regions in China show increasing returns to scale, suggesting that these regions should increase investment in health resources to achieve the desired output.

\subsection{Efficiency Ranking under Entropy Weight TOPSIS}

Table 4 shows the results of TOPSIS. According to the value of relative clossness, it can be seen that in 2018, the level of resource allocation among primary medical and health institutions varies greatly between provinces. Ranking to the value of relative clossness from top to bottom, The top three under the TOPSIS method are Guangdong, Jiangsu, and Hunan, andhe bottom three are Qinghai, Tibet, and Ningxia. The TOPSIS method also gives the ranking of effective DMUs: Guangdong, Jiangsu, Hunan, Zhejiang, Jiangxi, Chongqing, Shanghai, and Beijing.

\section{Conclusion}

Inter-provincial differences exist in the efficiency of primary medical and health institutions. In 2018, the efficiency of primary medical and health institutions was generally at a low level, with an average efficiency of 0.78 . Specifically, while 14 regions in China are in a relatively inefficient state of "inefficient technology" and "inefficient scale". There was a large gap in the relative closeness, which means that there were still differences in the allocation of health resources among primary medical institutions in various regions, and the differences are large. First, it is recommended to adjust and optimize the elements of health input. Responsible government departments should formulate reasonable health resource allocation standards, adjust and optimize health resources in a targeted way, plan and arrange the ratio of input and output to achieve the best output of health resources at the primary level. Based on the demand perspective, develop a reasonable layout of health resources. Under the current situation of rising 
Table 4. TOPSIS results of primary medical and health institutions in 2018.

\begin{tabular}{|c|c|c|c|c|}
\hline Regions & $\begin{array}{l}\text { Positive ideal } \\
\text { solution }\end{array}$ & $\begin{array}{l}\text { Negative ideal } \\
\text { solution }\end{array}$ & $\begin{array}{l}\text { Relative } \\
\text { closeness }\end{array}$ & Ranking \\
\hline Guangdong & 0.0930 & 0.2385 & 0.7196 & 1 \\
\hline Jiangsu & 0.0997 & 0.2048 & 0.6725 & 2 \\
\hline Hunan & 0.1306 & 0.2361 & 0.6440 & 3 \\
\hline Zhejiang & 0.1878 & 0.1406 & 0.4281 & 4 \\
\hline Jiangxi & 0.1850 & 0.1295 & 0.4118 & 5 \\
\hline Chongqing & 0.2234 & 0.0950 & 0.2983 & 6 \\
\hline Shanghai & 0.2818 & 0.0176 & 0.0589 & 7 \\
\hline Beijing & 0.2867 & 0.0133 & 0.0445 & 8 \\
\hline Sichuan & 0.0357 & 0.2038 & 0.8510 & 9 \\
\hline Henan & 0.0407 & 0.1889 & 0.8228 & 10 \\
\hline Shandong & 0.0468 & 0.1977 & 0.8087 & 11 \\
\hline Hebei & 0.0988 & 0.1469 & 0.5978 & 12 \\
\hline Hubei & 0.1051 & 0.1256 & 0.5444 & 13 \\
\hline Guangxi & 0.1335 & 0.0952 & 0.4162 & 14 \\
\hline Anhui & 0.1436 & 0.0848 & 0.3711 & 15 \\
\hline Yunnan & 0.1514 & 0.0757 & 0.3334 & 16 \\
\hline Guizhou & 0.1643 & 0.0628 & 0.2767 & 17 \\
\hline Shaanxi & 0.1668 & 0.0616 & 0.2698 & 18 \\
\hline Fujian & 0.1711 & 0.0568 & 0.2493 & 19 \\
\hline Shanxi & 0.1771 & 0.0581 & 0.2469 & 20 \\
\hline Liaoning & 0.1740 & 0.0564 & 0.2449 & 21 \\
\hline Gansu & 0.1804 & 0.0495 & 0.2152 & 22 \\
\hline Xinjiang & 0.1904 & 0.0371 & 0.1631 & 23 \\
\hline Inner Mongolia & 0.1941 & 0.0350 & 0.1529 & 24 \\
\hline Heilongjiang & 0.1935 & 0.0348 & 0.1523 & 25 \\
\hline Jilin & 0.1978 & 0.0319 & 0.1387 & 26 \\
\hline Tianjin & 0.2172 & 0.0123 & 0.0536 & 27 \\
\hline Hainan & 0.2205 & 0.0064 & 0.0283 & 28 \\
\hline Qinghai & 0.2231 & 0.0034 & 0.0151 & 29 \\
\hline Tibet & 0.2248 & 0.0029 & 0.0126 & 30 \\
\hline Ningxia & 0.2245 & 0.0026 & 0.0113 & 31 \\
\hline
\end{tabular}


urbanization rate in our country, population and resources are accelerating to the cities. The contradiction between the supply and demand of health resources between regions has become increasingly severe and significant, which means that the allocation of health resources is facing huge challenges. At this stage, it is necessary to develop a reasonable layout of primary health resources, and determine the total amount, structure, layout, and level of health resources so that matching supply and demand. Second, optimize and improve the primary health care service system to coordinate urban and rural development. Specifically, it can be expressed as: increasing input and support to primary medical and health institutions, starting from three aspects of human resources, hardware equipment, financial subsidies, and gradually improving the service capacity and level of primary medical and health institutions to increase their competitiveness and attraction force. Third, based on the input perspective, adjust and optimize the elements of health input. Within the primary medical and health institutions, the problem of unreasonable allocation of people, money, and materials is significant, and there is a serious waste of resources for health personnel and bed. Therefore, it is important to formulate reasonable primary health resource allocation standards, carry out targeted adjustment and optimization of health resources so that primary health resources can reach the optimal output.

The article makes an estimate of the efficiency of 31 regions in China from 2013 to 2018 and analyzes the current situation and existing problems. However, the influencing factors behind the problem have not been explored which has limited value for guiding policy at the government level. Future research can explore the influencing factors behind efficiency to gain a deeper understanding of the efficiency of China's primary medical and health institutions.

\section{Conflicts of Interest}

The authors declare no conflicts of interest regarding the publication of this paper.

\section{References}

Chen, T. (2015). Analysis on the Current Situation and Countermeasures of Rural GrassRoots Health Resources Allocation. Rural Economy and Science and Technology, 1, 232-234.

Chen, Y., Chen, Y. R., \& Ma, W. B. (2012). Intensive Use Evaluation and Potential Mining Analysis of Industrial Land Based on Bayes Discrimination. Resources Science, 34, 433-441.

Cheng, G., \& Qian, Z. H. (2012). Conceptual Framework and Measurement Method of Health System Efficiency Evaluation-Concurrently Discussing Methodology of Applied Data Envelopment Analysis. China Health Policy Research, 5, 52-60.

Fang, P. Q., \& Zhao, L. (2013). Research on Health Equity Realization from the Perspective of Health Resource Utilization Efficiency. Population and Development, 6, 74-83+ 18.

Fang, P. Q., Jiang, S., Yang, X. Y., \& Su, M. (2016). Discussion on Key Issues and Countermeasures of the Implementation of Hierarchical Medical System in China. Chinese 
Hospital Management, 11, 1-3.

Niu, Y. D., Zhang, Y., Ye, T., \& Zhang, L. (2018). Development and Current Situation of Medical Service Capacity in China's Primary Medical and Health Institutions. China Hospital Management, 6, 35-41.

Wang, X. Y., Yao, Z. R., \& Tian, K. (2017). Reflections on Problems Related to Graded Diagnosis and Treatment in China from the Perspective of Supply Side. China Hospital Management, 3, 21-23.

Xiong, W. T., Feng, Y. Q., \& Yong, L. Q. (2016). DEA Ranking Method Based on Public Weights and Ideal Decision Units. Systems Engineering, 34, 124-128. 